Zelnik's book is a kind of miniature in time and place of Tugan-Baranovsky's work. After presenting introductory material on the early nineteenth century (chaps. 1 and 2), it focuses on the factory in St. Petersburg in the crucial period of the Great Reforms. Separate chapters discuss (as did Tugan-Baranovsky) industrial growth, labor conditions, labor regulation, labor unrest, and the views of officials, industrialists, and publicists of the "labor question." Zelnik has mastered a vast quantity of rich materials and has handled with sophistication issues too numerous to summarize here. One strength of research pursued in the basic sources without the imposition of preconceived patterns is in the uniqueness of the subject matter revealed. Zelnik's people function within a Russian context of autocracy and nationalism rather than acting out predetermined roles as a European bourgeois ruling class and proletariat.

One thread that runs through the history is the widely held belief in the 1860 s -a kind of industrial populism-that the Russian worker, by virtue of his ties with the commune, would escape the degradation of his European counterpart, and Russian society would avoid the resultant social disruption. This proved false; but most of the Russian workers were still essentially illiterate peasants, many of the industrialists were unlettered Muscovite merchants, and the majority of the officials treated both groups in the paternalistic tradition of the old agrarian despotismresponsive to the injustices inflicted on the workers by the factory owners, viewing each as a lower social class, and yet punishing workers for the slightest attempt to act on their own behalf, as a grave threat to public order. Thus, even as late as the Nevsky strike of 1870 the minimum sentences imposed on its leaders by the court (which also rebuked the employers) were viewed as "exceedingly light" by the tsar, and harshened by administrative order. Zelnik, through his extensive research, and a clear presentation, is able to portray these nuances effectively. One hopes for more such studies that will lessen our reliance on Soviet monographs, which, as Zelnik rightly asserts (p. 3), have been the main source of our broader works of synthesis. Contrary to his assertion, we still need several levels of synthesis, both for the Russian field and for the comparative dimension of European and Russian history, which has been particularly neglected. Tugan-Baranovsky may have erred and misinterpreted some of the sources, but in his attempt at both broad interpretative synthesis and comparative history much has stood the test of time.

WiLLIAM L. BlackWELL New York University

CHERNYSHEVSKII: THE MAN AND THE JOURNALIST. By William $F$. Woehrlin. Russian Research Center Studies, 67. Cambridge: Harvard University Press, 1971. x, 404 pp. $\$ 12.50$.

Between that gray raznochinets of clerical background N. G. Chernyshevsky and the autocratic government he opposed there existed a secret complicity which created the style of an epoch and left a permanent stamp on the "Russian Idea." Without government-sponsored martyrdom, Chernyshevsky could never have entered revolutionary heaven, haloed by liberals and radicals alike. Indeed, he probably never even would have written What To Do? - a novel which may be compared in its influence to Pilgrim's Progress and in its style to the speech of some of Zoshchenko's characters, a novel the title of which Lenin echoed in his most famous 
pamphlet. Since Chernyshevsky's practical activities were characterized by a certain shlemielstvo, since his erudition was unassimilated (his ideas borrowed from Fourier, Feuerbach, and Belinsky and vulgarized), since his style was soggy, with its attempts at humor and deep seriousness extremely difficult to distinguish, it is only by recognizing and characterizing this complicity with his cultural environment that a biographer can still do useful work.

Already there is a vast literature on Chernyshevsky: there are his complete works, totaling sixteen volumes in Russian (including, in addition to much scholarly annotation, two versions of What To Do?), and then there are, from Pypin and Plekhanov to Steklov and Nechkina, the multivolumed studies, apologetic and tending toward hagiography.

We have available in English the long passages on Chernyshevsky in Venturi and Lampert and the small popularizing work, written with considerable gusto, by Francis Randall. This distinguished if somewhat abundant company has now been joined by William Woehrlin. He has written the fullest, most comprehensive, most judicious, and-as intellectual history-most "professional" account of Chernyshevsky's life and work available so far in English. He is less enthusiastic about revolutionary activity than Venturi, less speculative than Lampert, and considerably less ebullient and more judicious than Randall. His book truly and competently represents the present state of Chernyshevsky scholarship. Although it is true that he fails to answer them, he does at least by heavy implication raise two fundamental questions: Why did Chernyshevsky become a revolutionary? How did he come to have such incredible sway over so many minds, including even some rather good ones?

Perhaps a more fruitful approach to the materials of Chernyshevsky's life would not attempt so strictly to separate the events and products of that life from the hagiography they have created, but would rather resemble that of the mythographer to The Golden Legend. Woehrlin's book makes many corrections and emendations to past interpretations, but adds little. Far more interesting, not only for its wit and Gogolian drama, but because it places Chernyshevsky in the context of Russian culture, is the biography by Godunov-Cherdyntsev, the hero of Vladimir Nabokov's The Gift, and the reviews it elicits, as set forth in that extraordinary novel first published thirty-five years ago.

Sidney Monas

University of Texas, Austin

\section{OCHERKI PO ISTORII IUZHNYKH SLAVIAN I RUSSKO-BALKAN- SKIKH SVIAZEI V 50-70-E GODY XIX V. By S. A. Nikitin. Moscow: "Nauka," 1970. 328 pp. 1.51 rubles.}

This collection of articles by a leading Soviet historian deals with Bulgaria's economy and struggle for liberation, and Russian diplomacy and public opinion toward the South Slavs. Though disparate and specialized, the articles provide quite a cohesive picture of Russian policy and aspects of the Balkan economic and political situation between the Crimean and Russo-Turkish wars. Most of the selections appear for the first time; those previously published have been revised. Nikitin, a meticulous yet imaginative scholar, has made thorough use of Soviet archival and newspaper collections and Serbian and Bulgarian published sources. Much of the material comes from his massive unpublished doctoral dissertation, 